\title{
Industrial Development of Taiwan
}

\section{Susumu Yamamoto*}

\section{Introduction}

Although it is rare to come across many Taiwanese brand names outside of Taiwan, Taiwan is one of the largest PC (Personal Computer) exporters in the world. Many of the computers working in offices and schools with well-known brand names are actually produced by Taiwanese computer manufacturers within the framework of OEM (Original Equipment Manufacturing). It is said that nearly $80 \%$ of lap-top computers are actually Taiwanese made products.

Taiwan's GDP per capita was US\$12,462 in 2002 which was much less than that of Singapore and Hong Kong. Nevertheless, the Taiwanese record was well beyond the Korean GDP per capita, US\$8,802. GDP per capita is not the only measure of a nation's economic success. However, no one would disagree that Taiwan is any less successful than Korea.

Because of her unique industrialisation strategy and also her delicate position in international politics, Taiwan's economic and industrial success has not necessarily been discussed as much as Korea. This paper focuses on Taiwanese industrialisation from an industrial development strategy point of view. In particular, the electronics industry has been the driving force of Taiwan's industrial development.

The aggregated total of electric and electronics machinery industry grew by 238 times in thirty years from 1965 to 1994 . The Taiwanese electronics industry has been the largest export contributor to Taiwan. Therefore, discussion on industrialisation strategy of Taiwan can not be done without looking at electronics

Fig. 1 Electrical \& Electronics Machinery Production Index

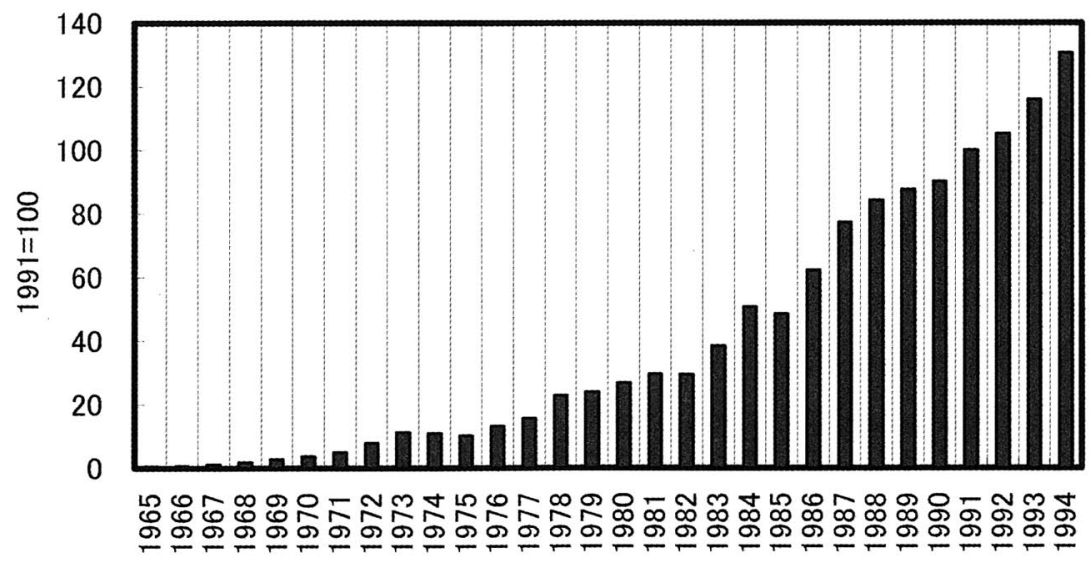

Source : Statistical Year Book of China, 1995, DG of Budget, Accounting and Statistics

* The professor of the College of Asia Pacitic Manegement, Ritsumeikan Asia Pacitic University 
industry.

This paper is an attempt to present an industrialisation strategy model for a developing country. One may call it a catch-up strategy model for a latecomer because a developing country has to overcome various obstacles due to being a latecomer. There aren't many successful cases of catch-up in industrialisation. However, Taiwan seems to show us a very unique catch-up strategy model which is different from Korea and other Asian neighbours.

The first few sections of this paper concentrate on a historical analysis of the industrial development of the Taiwanese electronics industry. There are a few slightly different views on the historical phases division of Taiwanese industrialisation. ") This paper will use the simplest definition of historical phases division. Based on the three most important industries which successively developed in Taiwanese industrialisation history, this paper takes three phases of Taiwanese industrialisation, the TV phase (the 60s to the 70s), the PC phase (the 80s) and the semiconductor foundry phase (the 90s).

\section{The TV Phase - Dawn of Taiwanese electronics industry}

The history of the Taiwanese electronics industry began in the early 60s. The first transistors assembly factory was built in 1961 in Taiwan. Major Japanese electronics manufacturers, Toshiba, Matsushita, Mitsubishi and NEC, established joint ventures with Taiwanese partners to build factories to produce black
$\&$ white television and other products for the

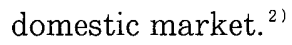

These were the very modest beginning of the industry. However, direct investment by the General Instruments of the US into Taiwan has been considered the most important in the early development history of the Taiwanese electronics industry. The General Instrument Corporation was a major US electronic component manufacturer. Attracted by relatively lower labour cost, it made a direct investment into Taiwan in $1964 .^{3)}$

In the late $60 \mathrm{~s}$, the Japanese TV manufacturers substantially increased use of transistors for their TVs. Increasing use of transistors achieved a few positive by-products, drastic improvement of productivity, quality and performance. Thanks to these achievements, the Japanese manufacturers increased their TV export to the US and gained a higher share of the US market. The US manufacturers' response to the Japanese counterparts' challenge was to relocate their factories to those countries with lower labour cost.

The 60s was the decade where the transition from black \& white TV to colour TV took place in the US market. In addition, the black \& white TV market reached a maturity phase where a new demand for replacement and additional TVs arose. While the market for large sized black \& white TVs with wooden cabinets remained lucrative, smaller sized black \& white TVS became more popular among consumers. $^{4)}$

Although the Taiwanese TV industry was 
started by the Japanese-Taiwanese joint venture, the industry's substantial development took place when the US manufacturers established their export oriented joint ventures mainly located in newly established export processing zones. ${ }^{5)}$ Those US manufacturers, such as RCA, Zenith, Philco, Motorola and Admiral chose Taiwan for their production base to cater for the US market not only for lower labour cost but also for the reliable component supply by the General Instrument and Taiwanese government's foreign investment promotion policy.

The Taiwanese government introduced various promotion measures such as bonded warehouse scheme and duty drawback scheme for export oriented production activities. The government also tried to encourage improvement of local content ratio of Taiwan made electronic products by imposing high import duty on not only finished products but also components. General Instrument and other joint ventures started electronic component production in Taiwan. ${ }^{6)}$

Thanks to these developments, television became the leading sector of the Taiwanese electronics industry and, at the same time, a leading sector of export. As an export destination, the US market was dominantly the most important one for the Taiwanese television industry. In 1976, the share of the US among those Taiwanese TV export destinations was 94\% for colour televisions and $79 \%$ for black \& white televisions. ${ }^{7)}$ Because of this very reason, the Taiwanese TV industry suffered from an external shock.

The US TV industry has been suffering pressure from their Japanese counterparts. Not only price competition, but also performance competition particularly in compact sized TV segments became a serious challenge for them. The US industry took legal actions in the late $60 \mathrm{~s}$.

As early as 1970, the US Treasury Department, in response to the industry's petition, ruled that Japanese television sets were imported to the US at a dumping price and imposed a 9 percent dumping charges on those television imports from Japan. In parallel, Zenith sent a petition to the Treasury Department to request countervailing duties on Japanese imports on the ground that those Japanese manufacturers were receiving government subsidies. ${ }^{8)}$

Zenith, in particular, continued to send complaints to the US government departments throughout the 70s. In addition, a labourmanagement coalition of component suppliers for the US TV industry and a small TV manufacturer called COMPACT (Committee to Preserve American Color Television) petitioned, in 1976, to the ITC (the International Trade Committee) for import relief. ${ }^{9)}$. These legal actions eventually led to a voluntary export restriction by the Japanese manufacturers.

In 1977, the ITC negotiated with the Japanese government to conclude a voluntary Orderly Marketing Agreement (OMA) by voluntarily restricting Japanese finished television sets exports to the US to 1.56 million 
sets a year for three years. This series of legal actions by the US TV industry brought about an ironical consequence.

By the end of the 70s, most of major Japanese TV manufacturers had established their TV production facilities in the US. On the other hand, the major US TV manufacturers relocated their TV factories to lower labour cost countries such as Taiwan. As a result, TV imports from Japan declined drastically while imports from other countries increased substantially. The US government became pressured this time to take a countermeasure against the TV imports from other countries such as Taiwan and Korea.

The US government negotiated with the Taiwanese and Korean governments to extend the OMA to their TV exports to the US and concluded the agreement in 1978. The OMA for Taiwan hit the Taiwanese TV manufacturing industry hard. In 1978, immediately after the
OMA for Japan was concluded, Taiwanese colour television exports were increased by 2.4 times compared with the previous year. Nevertheless, Taiwanese exports declined by $60 \%$ as soon as the OMA for Taiwan took effect in 1979.

Furthermore, the Taiwanese TV industry was hard hit again by the imposition of the US antidumping countervailing duty six month after the OMA for Taiwan was ended in 1982. Although the Taiwanese TV industry recovered its production volume of television, many local TV manufacturers started their business diversification to the computer peripherals business.

Throughout the 80s and 90s, their production of computer monitors increased remarkably. The PC boom in the US in the 80 s and the global IT revolution contributed to this Taiwanese success in PC monitor production.

Fig. 2 CTV, B\&W TV and Computer Peripherals Production in Taiwan

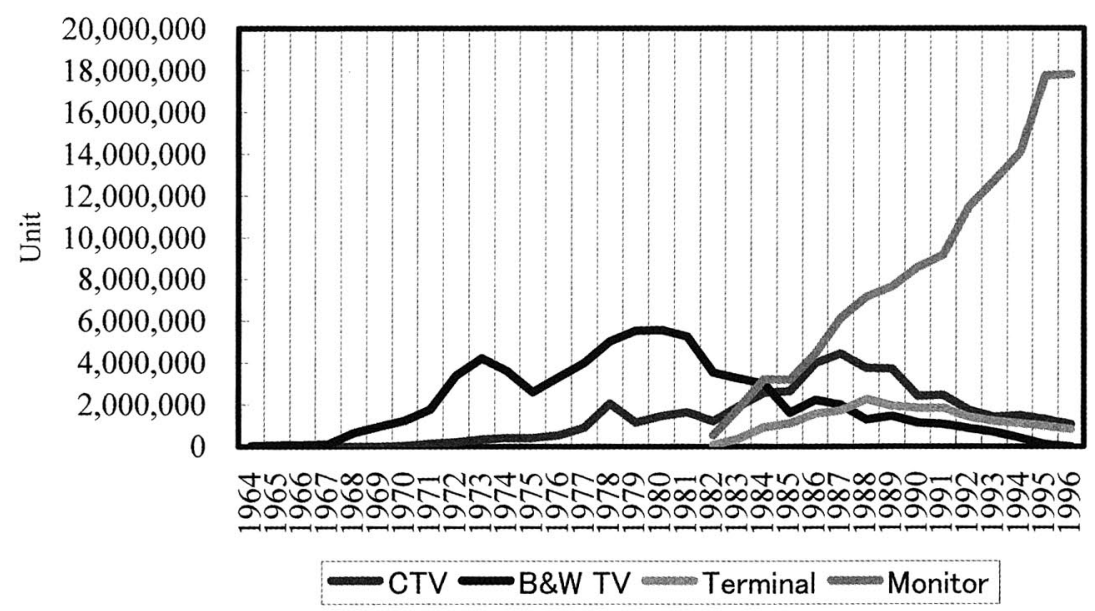

Source : D. Moon, Taiwan's Long Term Economic Data, Keiso Shobo, 2002 


\section{The PC Phase - Emergence of the OEM Giant}

In March 1964, a Japanese consumer electronics manufacturer, Sharp, launched the world first electronic calculator, CS10-A, by using transistors. Seven months later, Sharp's rival manufacturer, Canon, launched its own electronic calculator. Since then, electronic calculators replaced conventional mechanical calculators and electric relay calculators. Because of superior performance, electronic calculators became the dominant products for business-use calculation. Due to the rapid growth of the market, intensified competition, and decline in the cost of transistors, the price of calculators steeply declined. The electronic calculators market grew further.

Many electronics manufacturers entered this booming market. In 1970, 23 manufacturers were competing against each other in the electronic calculators market in Japan. ${ }^{10)}$ The expanding electronic calculator market in Japan contributed to new development in the semiconductor industry in the US. A medium sized electronic calculator manufacturer, Busicom, contacted in 1969 a newly established semiconductor venture business, Intel, to develop an innovative programmable LSI (Large-Scale Integrated circuit), now it is called MPU (Micro Processor Unit). In 1971, Intel launched the world first MPU, 4004. ${ }^{11}$

In the 60s, IC for electronic calculators was specially designed and produced on a custom made basis. For this reason, prices of those customised ICs (ASIC) did not become cheaper as quick as other mass-produced ICs. However, as early as the beginning of the 70s, multipurpose LSI was developed. This multipurpose LSI made fast cost reduction possible. ${ }^{12)}$

Texas Instrument (TI) launched a new type of One-Chip LSI specially designed for electronic calculators (TMS 1000 series) at a competitive price. If one connected this type of one-chip LSI with other peripherals such as a ten-key board and a small display, one could easily make a marketable electronic calculator. In addition, the one-chip LSI could be applied not only to calculators but also to electronic clocks and videogame machines. Because of simplicity of production process for these products, entry into this segment of business did not require large capital. Many small and newly established companies in Taiwan made an entry to this business. ${ }^{13)}$ Some of them led to many spin-out companies. The Predecessor of ACER was one of them.

Electronic calculators became a leading business sector after $\mathrm{TV}$, radio and tape recorder for the Taiwanese electronics industry. According to the Taiwan Industrial Production Statistics Monthly, production of electronic calculator was increased from 4,784 in 1972 to $43,695,625$ in 1984 . The industry grew by more than 9,000 times in volume terms in just over a decade.

Some of the newly established spin-out companies started a new business to develop and produce videogame machines by using their knowledge and experience accumulated through electronic calculator development and 
Fig. 3 Production of Video Games and PCs

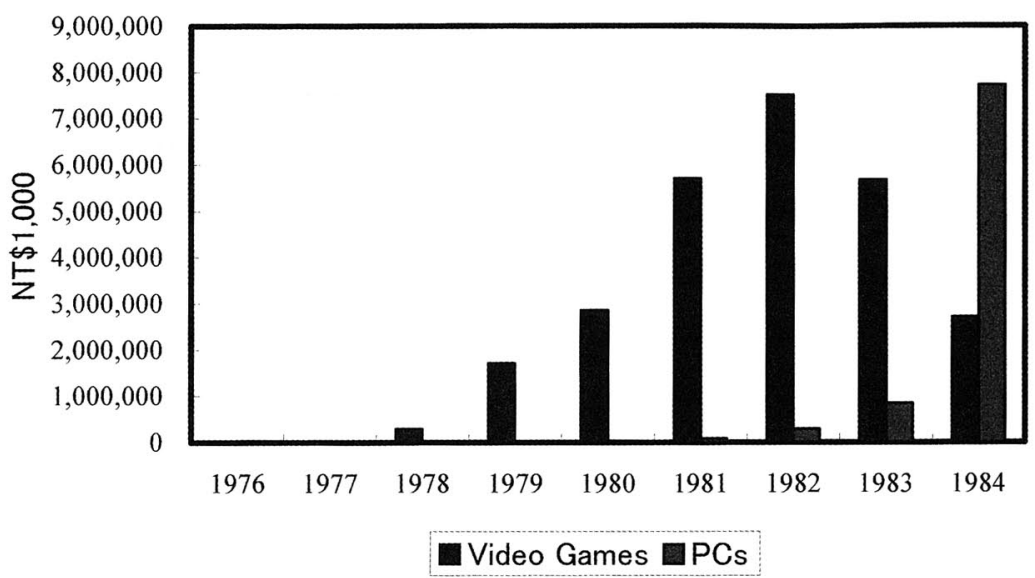

Source : Industrial Production Statistics Monthly, Taiwan Area, July 1979, July 1985

production in the late $70 \mathrm{~s}$. In this period, micro processors made by US manufacturers such as Intel and Zailog became widely available at a reasonable price. By using these microprocessors, these Taiwanese videogame manufacturers produced a large number of videogames for the booming domestic market. However, the videogame boom in Taiwan caused the authorities to be concerned over negative influence to juveniles.

The government, in March 1982, banned production and sales of videogames in Taiwan except for exports. ${ }^{14)}$ By the time when this go vernment's action was taken, over twenty manufacturers were assembling Apple II clones. The government's ban accelerated this new direction to develop clones of Apple II which was the most popular PCs in the US. The reasons that made such switch of business domain possible were;

1) Some of those manufacturers gained technical know how on CRT controls through their television production experience,

2) Some others accumulated technical knowledge of microprocessors through their electronic calculators development and production;

3) Apple II used 6502 for its MPU. Many videogame manufacturers had used same type of microprocessors.

Many of their Apple II clones were exported to overseas markets. Apple Computer lodged a complaint to the US ITC by alleging that those Apple II clones were violating its intellectual property right in January 1983. In response to Apple's complaint, the ITC ruled that PCs by 21 foreign manufacturers including 10 Taiwanese should be banned from being exported to the US market in December 1983. ${ }^{15)}$

In parallel, some Taiwanese PC manufacturers started to develop clones of IBM PCs that had been launched in August 1981 and became very popular PC for business users. For this development work, a leading governmental 
research body, ERSO (Electronics Research and Service Organisation) played a crucial role.

Just like Apple, IBM also took legal actions against those IBM PC clone manufacturers on the grounds that those clone manufacturers were violating IBM's intellectual property rights. However, some of those Taiwanese clone manufacturers accused by IBM were using a BIOS (Basic Input Output System) which had been developed by ERSO. In response to IBM's complaint, ERSO modified its BIOS and negotiated with IBM to acknowledge that the BIOS was not violating IBM's intellectual property rights.

IBM continued its legal battle against those clone manufacturers. However, the number of those cases where Taiwanese manufacturers PC were banned to export to the US steadily decreased. ${ }^{16)}$ Instead, price competitiveness of those Taiwanese PCs attracted business interest of foreign computer manufacturers. The Taiwanese PC industry grew at a very high pace in the late $80 \mathrm{~s}$. ERSO continued to develop IBM compatible PCs and transferred its developed technology to local manufacturers.

In line with their fast growth, some of major Taiwanese PC manufacturers started their efforts to establish their own brand names. They established their sales and marketing bases in the US and strengthened their marketing efforts. However, the world PC industry entered into a cutthroat price war in the early $90 \mathrm{~s}$.

Most major PC manufacturers in the US and other industrialised countries substantially reduced the retail price of their PCs. Consequently, price competitiveness of Taiwanese PC manufacturers was significantly eroded. In addition, those well-known brand names got into the low-end market distribution channels as well. The market competition in the US became tougher for Taiwanese manufacturers with less-known brand names. Taiwanese PC manufacturers' fast growth was stalled in this price competition.

The Taiwanese PC manufacturers that faced the most significant challenge in its history reshaped their business strategy. By shifting their main business focus from own brand name marketing to OEM, they tried to compensate for the disadvantage of having lessestablished brand names. During this price war period, American and European PC manufacturers were also under pressure to cost cutting further. Compaq, for instance, became one the largest clients for Taiwanese OEM PC manufacturers.

Leading Taiwanese PC manufacturers, ACER and MITAC, used to have 70-75\% share of own brand products in the total shipment. However, their share of own brand products declined to $31 \%$ on average. ${ }^{17)}$ This strategic change of business focus laid the foundation of Taiwanese electronics industry as the OEM giant.

In 2000, Taiwan's IT related equipment exports including PCs totalled 28 billion US dollars. In the early $90 \mathrm{~s}$, the weight of the US and European markets were the largest. However, the share of the Japanese market in 
Table 1 Taiwan's IT Equipment Exports

(100 Million US\$)

\begin{tabular}{|l|c|c|c|c|c|c|c|c|}
\hline & 1993 & 1994 & 1995 & 1996 & 1997 & 1998 & 1999 & 2000 \\
\hline The US & 47.5 & 42.0 & 56.8 & 65.4 & 86.3 & 84.6 & 86.1 & 89.8 \\
\hline Europe & 31.5 & 33.9 & 45.7 & 56.5 & 62.0 & 69.3 & 72.4 & 85.2 \\
\hline Japan & 2.7 & 6.7 & 18.4 & 22.2 & 18.6 & 16.8 & 29.2 & 46.8 \\
\hline Others & 10.3 & 24.1 & 33.9 & 38.6 & 44.4 & 41.1 & 51.4 & 58.8 \\
\hline Total & 92.0 & 106.7 & 154.8 & 182.7 & 211.3 & 211.8 & 239.1 & 280.6 \\
\hline
\end{tabular}

Source : Ministry of Finance, Monthly Trade Statistics, and [Mizuhashi 2001]

Taiwanese IT equipment exports noticeably increased.

Taiwanese PC industry faced challenges by soaring labour cost and currency fluctuation throughout its history. It managed the challenge by relocating their production facilities into continental China. Combining their own factories in continental China together with domestic production, total production of Taiwanese electronics industry reached 47 billion US dollars in 2000. Taiwan is now the largest producer and supplier of IT hardware in the world.

\section{The Semiconductor Phase - Broadened Base for the OEM Giant}

It was pointed out in the earlier section of this paper that the year of 1966 when General Instrument established its transistor factory in Taiwan marked the beginning of Taiwanese electronics industry. Following the US semiconductor and electronic component manufacturers, other leading electronics companies such as Texas Instruments and Phillips built their factories in Taiwan. However, all of these transistors and other electronic component factories were concentrating on labour intensive assembling processes rather than technology and capital intensive semiconductor manufacturing process. It is natural for those foreign manufacturers to make efforts to lower total production cost by taking advantage of lower labour cost in Taiwan.

The Taiwanese government that had been urged to promote its own industry further in the turbulent international political situation was considering a policy to upgrade its electronics industry. In October 1971, Taiwan was expelled from the United Nations because of the continental China's new membership. Political pressure from continental China was being brought to bear on Taiwan.

The authorities requested a government promoted private consulting body of government officials, industrialists, scientists and engineers to discuss the future leading sectors of the Taiwanese electronics industry and necessary policy measures to promote such promising sectors. ${ }^{18)}$ Leading members of the consulting body recommended the government to upgrade the Taiwanese electronics industry by introducing upstream process or 
semiconductor manufacturing technology from the US in 1974. They also pointed out that the government should play an active role in allocating government financial and human resources for this project, because the private sector of Taiwan consisted of small and medium sized firms without sufficient resources. ${ }^{19)}$

There existed scepticism in the government about the project because of its concern over technological feasibility and a large amount of required fund to launch the project. However, the government decided to implement the project in 1974 and to allocate 10 million US dollars for four years. ${ }^{20)}$ In line with the policy, a specialised governmental research institute ERSO (Electronics Research Service Organisation) was established under the Industrial Technology Research Institute (ITRI) in $1974 .^{21)}$

The government first requested US major semiconductor manufacturers to consider semiconductor manufacturing technology transfer contract, and chose RCA. Under the government plan, the US made semiconductor technology was first transferred to ERSO where the first pilot plant was built. Technology and know-how digested in ERSO was then transferred to a newly established public corporation, United Microelectronics Corporation (UMC) which was established in $1980 .{ }^{22)}$

Despite being fully supported by ERSO and launching various ICs for commercial purposes, digital watches and calculators, the business of UMC initially faced difficulties. ${ }^{23}$
However, its business became stabilised because it succeeded in cultivating the telecommunication IC market in the US. Based on the success of the first four years project of technological upgrading of the Taiwanese electronics industry, the Taiwanese government invited a successful technological top executive of Texas Instrument with Chinese origin, Dr. Morris Chang, to take up the post of the chief of ITRI in 1985.

The ultimate goal that Dr. Chang was assigned to achieve was, off course, to firm the foundations of the Taiwanese electronics industry up and to make it sustainable. For his goal, he was required to satisfy two conditions simultaneously. Firstly, he needed to build a large-scale semiconductor factory to achieve economy of scale. ${ }^{24)}$ Secondly, small and medium sized enterprises in Taiwan preferred to have their small but own semiconductor factories.

Dr. Chang came up with a practical solution to establish a large scale semiconductor factory which those Taiwanese small and medium sized enterprises could use. This idea led to a new business model, "semiconductor foundry." Foundry in this context implied that a semiconductor factory did not produce any product under its own brand name but manufactured semiconductors solely for a third party. To materialise this idea, TSMC, Taiwan Semiconductor Manufacturing Corporation, was established in 1987. ${ }^{25)}$

In line with the steep growth of the global semiconductor industry, semiconductors 
became further diversified. From massproduced memory chips to specialised ASICs, there arose a demand for a wide range of semiconductors. In the $90 \mathrm{~s}$, there was an increase in the number of so-called fab-less semiconductor companies which specialised in designing semiconductors not in manufacturing. They placed an order to a semiconductor manufacturer to produce a particular kind of semiconductor based on their specifications. The semiconductor manufacturer which produced its own semiconductors had to squeeze such a third party order into its own production schedule. For this reason, lead time for such specialised semiconductor production was not stable. Therefore, the new business model, foundry, which specialised in semiconductor production for a third party fitted perfectly into the niche market.

The foundry business model has a few outstanding advantages. First, a foundry semiconductor manufacturer can achieve economy of scale by gathering manufacturing orders from multiple clients. By doing so, the foundry can strengthen its cost competitiveness. Second, even small and medium sized semiconductor companies without manufacturing facilities can offer their products by using a foundry. They can strengthen their competitiveness in designing and engineering capabilities and/or focus on marketing and after sales services.

On the other hand, there have been some critical views on the success of the foundry business model. Without accumulation of intellectual property, Taiwan did not have any other choice but to concentrating on the foundry business. ${ }^{26)}$ In the 90s, a continuous decline in the manufacturing part of the value chain has been observed in the manufacturing industry. This is called "smile curve" phenomenon. Under these circumstances, a foundry has to make continuous efforts to reduce production cost to secure its profit rate.

Regardless of these critical views, the Taiwanese foundries have been steadily growing. Their success seems to be because of several reasons. First, they did not, unlike their Korean counterparts, enter risky DRAM business. Second, they instead focused on ASIC and other specialised semiconductor businesses. Third, they cautiously planned their investment strategy rather than making excessive investments. These make a sharp contrast with their Korean counterparts, mainly conglomerates or Cheabols.

\section{Taiwan as a Successful Catch-Up Strat- egy Model}

Taiwan's success story of economic development is very unique in many ways and quite different from Korea which has attained her economic development during almost the same period of history. This section focuses on some analytical discussions from a few different angles on the success story of the Taiwanese electronics industry to find out the essence of its catch-up strategy.

\section{5-1. Small and Medium-sized Enterprises - Tradition of Venture Businesses}

It has been pointed out by many that small 
and medium-sized enterprises (SMEs) have been the driving force behind the economic development of Taiwan. ${ }^{27)}$ Leu pointed out some outstanding features of Taiwanese SMEs in Taiw an's economic development. ${ }^{28)}$ Firstly, SMEs in Taiwan have been export oriented, while large corporations have been mainly government owned or public corporations concentrating on the financial sector and, heavy and chemical industries catering to the domestic market.

Secondly, SMEs have not been a part of a conglomerate. In other words, they have not been a part of Keiretsu. They are independent in terms of business and finance. Thirdly, they have grown in close linkage with foreign capital. Foreign capital has sometimes been partners of joint ventures with Taiwanese SMEs. At other times, foreign capital has been a major marketing channel for them. Fourthly, Taiwanese SMEs have been the most important contributors to Taiwan's exports and economic development. These can be summarised in Fig. 4.
Having understood that the economic development of Taiwan has been led by many export oriented independent SMEs, there arises the question of why an industry with many SMEs could achieve international competitiveness. Leu pointed out that labour costs in Taiwan were only a third compared with Japan. He stressed that labour cost for SMEs was even much lower even than that of large firms in Taiwan. ${ }^{29}$

Sato gave, in addition to labour costs, an explanation of the Taiwanese SMEs' competitiveness that they formed business networks where a highly specialised division of labour existed. ${ }^{30)}$ Taiwanese SMEs usually specialise in a particular part of an entire production process. By forming business networks, they achieved a few significant advantages in international competitiveness.

Sato argued that they could lower business risks and acquired flexibility to adapt themselves to changes in the business environment. ${ }^{31)}$ For instance, the Taiwanese electronics

Fig. 4 Economic Development of Taiwan - Actors

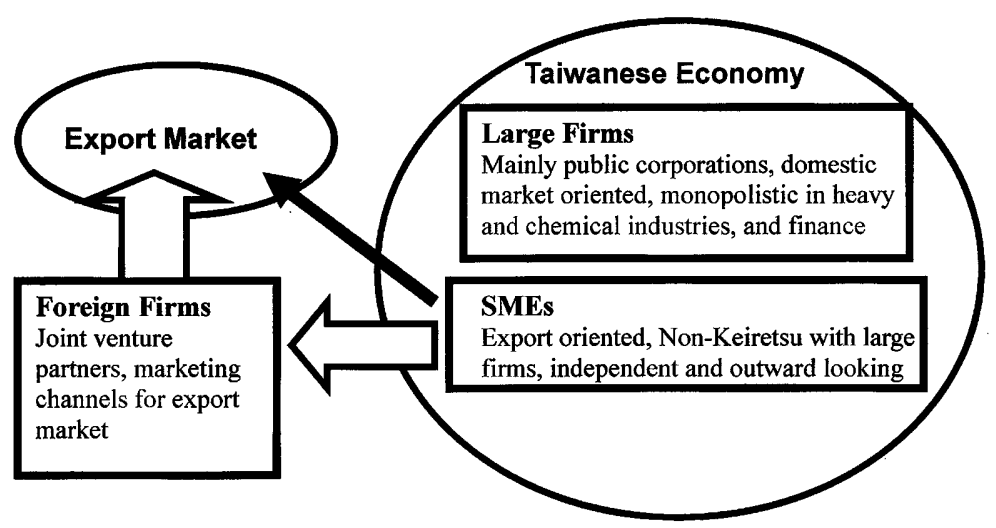

Source : Industrial Production Statistics Monthly, Taiwan Area, July 1979, July 1985 
industry has been repeatedly suffering from drastic changes within the business environment. In response to OMA and anti-dumping countervailing duty for the TV manufacturing industry in the late 70 s and the early 80 s, they made a shift in strategic focus from TVs to computer peripherals such as monitors.

$\mathrm{He}$ also pointed out that highly specialised division of labour brought an economy of scale to these SMEs. ${ }^{32)}$ A SME that has an autoinsertion machine for electronic printed circuit boards receives orders from other members of the network. By gathering these orders, the SME specialising in component insertion onto printed circuit boards achieves economy of scale. Furthermore, those specialised SMEs have attained dynamic economy of scale through a collective accumulation of know how.

The other aspect of the competitiveness of Taiwanese SMEs is entrepreneurship and spinout. For example, from 1986 to 1987 when exports of IT products grew rapidly, almost a thousand companies made new entries into the market. ${ }^{33)}$ As soon as they find business opportunity, Taiwanese businessmen and businesswomen try to entry into the market. Such nimble moves are not possible for bureaucratic big businesses. Only SMEs where the owners are ready to take business risks can make such quick business decisions.

It has to be remembered that many of the major PC manufacturers in Taiwan are spin out companies. ACER, for example, was founded by five co-founders and 11 employees in 1976. Stan Shih, chairman and CEO, used to work for Unitron and Qualitron where he developed the first penwatch and Taiwan's first calculator prior to founding ACER. ${ }^{34)}$

An able young man who graduated from a university with an engineering background joined an SME, achieved successful development and made a spin-out to found his own company. This is a typical success story of Taiwanese SMEs. It should be also noted that many promising young university graduates join SMEs in Taiwan.

\section{5-2 International Business Environment and Taiwanese SMEs}

The international business environment has not always been favourable to Taiwanese SMEs. As discussed in the previous sections of this paper, OMA, antidumping duties, govern ment's ban on videogames, intellectual property law suits and cut throat price competition claimed many victims. Nevertheless, there always remained some capable survivors that became internationally competitive players by coping with the new business environment.

On one hand, such serious business challenges made Taiwanese SMEs more competitive. On the other hand, only those SMEs that survived difficult times could set the standard for Taiwanese SMEs.

When Taiwanese SMEs faced appreciation of Taiwanese currency and soaring labour cost, they made a choice to establish their subsidiaries in continental China which had been politically hostile to Taiwan. They took political and 
business risks by making pragmatic business decisions.

It is also important to note that many Taiwanese electronics manufacturers including semiconductor foundries chose to be OEM suppliers, although leading Taiwanese PC manufacturers such as ACER made serious efforts to build up their own brand names. Remaining an OEM supplier may involve various disadvantages such as lower profit rate due to the smile curve effect. Nevertheless, an OEM supplier does not have to invest heavily in establishment of costly and risky marketing channel development and advertisement.

The Taiwanese electronics industry became the largest supplier of PCs and computer peripherals in the 90s. In 1994 for instance, 77\% of laptop type PCs exported from Taiwan was OEM or ODM (Original Design Manufacturing : an advanced form of OEM) while 40\% of desktop PCs and $67 \%$ of monitors exports were OEM/ODM. ${ }^{35)}$ OEM was a strategic decision made by Taiwanese electronics manufacturers. As Hirakwa pointed out, OEM has been a development process of the electronics industry in Taiwan. Leading PC manufacturers in Taiwan are exporting their PC on an ODM basis. ${ }^{36)}$ Furthermore, they developed innovative global logistics systems to become even stronger OEM suppliers. ${ }^{37)}$ To this extent, Taiwanese electronics manufacturers' OEM strategy can not be considered as occupying a subordinate position in the global economy.

\section{5-3 Government's Role in Industrial Develop- ment in Taiwan}

There still exists some controversy over the government's role in Taiwan's industrial development. Sato, for example, is rather dismissive of the government's role. He argued that protection policies and preferential taxation did not successfully promoted domestic industries. ${ }^{38)}$ Wade, who emphasises the importance of the government's role in Taiwan, admits that many studies from the neoclassic side of the debate consider Taiwan's industrialisation as a typical example of neoclassical industrialisation recipe. ${ }^{39}$

In comparison with the Korean Government that has had a strong dirigisme tradition, the Taiwanese government's role was less intervening. Nevertheless, this does not mean that the Taiwanese government has underplayed its role in the industrialisation of the country. By discussing the successful development of Taiwanese SMEs, Wade states;

"However, while they (Taiwanese firms) have been able to reap technological economies of scale by virtue of the export market, their small size has limited their ability to reap organisational economies of scale compared with the Korean conglomerates (in the purchase of inputs, in international marketing, and in cross-subsidization of $R \& D)$. Therefore the role of the state has been especially important in building technological competence in advanced electronics. All the more so because the multinationals with subsidiaries in Taiwan had no interest in relocating high value-added 
production there until recently; they valued it mainly as a site for the more labour intensive phases of production." ${ }^{m 0)}$

While the Korean government exercised its intervention into business activities and the market by carrot and stick, the Taiwanese government contributed to industrialisation by $\mathrm{R} \& \mathrm{D}$ and technology dissemination through training and spin-out.

Ying-yi Tu explains the role of the Taiwanese government in $R \& D$ and technology dissemination;

"The late 1970s were years during which the government forged closer ties with the electronics industry. Government's contributions came first in the form of setting up ERSO, which developed research in electronics technology and helped bring in and disseminate specific industry-related skills and technology in an attempt to raise the level of worker skill. ERSO also became an important source of technology and personnel for the electronics industry. Second, government established the III, which not only aided in the computerisation of government departments, but also groomed experts in the information field and encouraged the use of computer information, thereby promoting the development of the IT and electronics fields among the general population." ${ }^{41}$

In 1973, the Ministry of Economic Affairs (MOEA) founded ITRI (the Industrial Technology Research Institute as a government funded a non-profit organisation to promote research and development of industrial technology. Although it started as a modest sized research organisation with government funded three laboratories (Union Industrial Research Laboratory, Mining Research and Service Organisation, and Metal Industrial Research Institute), it developed to a large and leading technological research organisation in a few decades. It has altogether 4,611 researchers working on various industrial research works and also training of private firms' engineers. ${ }^{42}$

Under ITRI, the Electronics Industrial Research Centre was founded in 1974 to undertake electronics research activities. In 1974, in line with the government's IC indigenisation plan, the centre undertook to establish a model factory and also basic technological research works on IC manufacturing. The centre, under a technology transfer contract with RCA of the US, succeeded in producing prototypes of 7 micron meter class CMOS in 1979. The centre's CMOS became successful not only in research but also commercially, and were sold well to third parties. Based on the success, the first Taiwanese IC manufacturer, the United Microelectronics, was founded in 1980 as a government-industry joint venture. To this company, thirteen research experts on semiconductor manufacturing joined from the centre. ${ }^{43}$

The research centre developed to become the Electronics Research and Service Organisation (ERSO) in 1979. In the early 80s when IBM PC (personal computer) became a worldwide hit, ERSO developed a prototype of IBM PC clone and transferred its technology and technical know-how to the Taiwanese PC clone manufacturers such as ACER. This ERSO's 
technological supports firmed up the Taiwanese PC manufacturers' fundamental technological capability.

Throughout the development of the Taiwanese electronics industry, the Taiwanese government first cleared up technological and sometimes legal problems through government funded research bodies by funding those research activities. Those research bodies have been not only sources of technology and knowhow, but also important sources of technological experts. They also worked as training centres for engineers who were working for the private industry.

In such way, the Taiwanese government firstly set its vision, secondly funded basic researches, thirdly organised technology transfer mainly from the US, and fourthly retransferred digested technology to the private sector. Therefore, it is fair to say that the gov ernment's support of the private sector through $R \& D$ and technology transfer firmed up the technological foundation of the Taiwanese electronics industry.

\section{Conclusion}

It is true that brand names are largely dominated by economy of scale. Once a brand name is established in the international market, it does not cost as much to maintain it as it did to establish. For many developing countries, it may be a dream to establish an own brand name like IBM and Sony. However, these established brand names were frontrunners in many senses when they launched their new business.
To this extent, establishing a brand name in the international market place involves very costly efforts and does not necessarily promise any success.

Taiwan's success as an OEM giant seems to teach us a strategic option of catch-up strategy in a pragmatic approach for a latecomer. Without many internationally recognised brand names, the Taiwanese electronics industry focused on new business domains by achieving economy of scale through business networking. By remaining the most competitive OEM supplier in the world, it attracted many major brand names to outsource their production.

Their strategic decision to be OEM suppliers certainly has a lot to do with its unique SME dominant industrial structure. Although SME has at times negative implications such as subordinate positioning and/or low profit in other countries, Taiwanese SMEs have been the independent and innovative driving force of the economic development.

The unique government-industry collaboration through R\&D, technology transfer and technological experts transfer played a pivotal role in industrialisation of Taiwan. The government funded research bodies in Taiwan digested transferred technologies within a short period and re-transferred to the private sector. Although the Taiwanese government's role in industrialisation is very different from that of Korea, it's visionary commitments in $R \& D$ and technology transfer undoubtedly contributed it's industrialisation. 


\section{$<$ Notes $>$}

1) For instance, [Leu 1988], 249-251p., and, [Mizuhashi 2001], 2p.

2) [Leu 1988], 249-250p.

3 ) [Mizuhashi 2001], 1p.

4) [Porter 1983], 467-469p.

5 ) [Sato1989], 134p.

6) [Mizuhashi 2001], 8p.

7 ) [Mizuhashi 2001], 16p.

8 ) [Porter 1983], 484-496p.

9) [Porter 1983], 496p.

10) [Shintaku 1994], 192-194p.

11) [Tanimitsu 2002], 43p.

12) [Arai 1996], 42p.

13) [Mizuhashi 2001], 18p.

14) [Mizuhashi 2001], 21p.

15) [Mizuhashi 2001], 22p.

16) A decrease of intellectual property violation cases by Taiwanese PC manufacturers was partly due to reorganisation of Taiwanese intellectual property legal framework and strengthening of control by Taiwanese legal authorities.

17) [Mizuhashi 2001], 33p.

18) Although Mizuhashi, [Mizuhashi 2001], wrote that the government's request for the study was in 1973, Tanimitsu, [Tanimitsu 2002], clearly stated that the request for the study was given in 1972 . This paper follows Tanimitsu's statement.

19) [Tanimitsu 2002], 201-202p., and [Mizuhashi 2001], $43 \mathrm{p}$.

20) [Mizuhashi 2001], 43p.

21) [Tanimitsu 2002], 202p.

22) [Tanimitsu 2002], 203p.

23) [Tanimitsu 2002], 203p.

24) Economy of scale typically in semiconductor industry plays an important role. Not only dynamic economy of scale or learning by doing, but also static economic of scale has an important role. Semiconductor production has increasingly involved complicated chemical and physical processes which can not be viable in a small scale factory.

25) For establishment of TSMC, ERSO played a crucial role as well. It seconded totally 144 senior executives and engineers to TSMC. [Tanimitsu 2002], 203p. discusses the business environment in Taiwan behind the establishment of TMSC in details.

26) [Nihon Keizai Shimbun 1997], Morning edition, 24 December 1997

27) For example, see [Leu 1989], and [Sato 1996]

28) [Leu 1989], 41-42p.

29) [Leu 1989], 56p. According to Leu, SMEs' average labour cost is $78.6 \%$ of large firms' average.

30) [Sato 1996], 104-110p.

31) [Sato 1996], 108p.

32) [Sato 1996], 109p.

33) [Mizuhashi 2001], 25p.

34) [Chow, Holbert, Kelly and Yu 1997], 450-451p.

35) [Hirakawa 2001], 51p.

36) [Hirakwa 2001], 52-53p. OEM usually implies that designing of products is done by a final product manufacturer with its established brand name. However, a particular case where even designing of final products is done by an OEM manufacturer is referred to as ODM (Original Design Manufacturing). ODM is considered as an advanced form of OEM.

37) For example, MITAC's "Manufacturing and Global Logistics", and ACER's "Fast Food Business". See [Mizuhashi 2001], 33p. and 36p.

38) [Sato 1996], 88p. 
39) [Wade 1990] 52p.

40) [Wade 1990] 103p. In this quotation, the author inserted "(Taiwanese firms)" for convenience of readers.

41) [Ying-yi Tu 2001] 277p.

42) [ITRI 2003]

43) [Mizuhashi 2001] 44-46p.

\section{$<$ References $>$}

[Arai 1996] : Mitsuyoshi Arai, "Nichi-Bei no Denshi Sangyo (in Japanese : Electronics Industry of Japan and the US)", Hakuto Shobo, 1996

[Chow, Holbert, Kelley and Yu 1997] : I. Chow, N. Holbert, L. Kelley and J. Yu, "Business Strategy - An Asia Pacific Focus", Prentice Hall, 1997

[Hirakawa 2001] : Hitoshi Hirakawa, "NIEs no Yushutu Syudogata Hatten to Sekai Keizai (in Japanese : Export Oriented Development of NIEs and the Worl Economy)", in H. Hirakawa and K. Ishikawa ed., "Shin Higashi Asia Keizairon (in Japanese : New East Asian Economy)”, Minerva Shobo, 2001

[ITRI 2003] : Institute of Technology Research (Taiwan) official website, http://www.itri.org.tw/eng/index.jsp

[Leu 1988]: Shinkei Leu, "Denshi Sangyo-Sangyo Kodoka no Frontier (in Japanese : Electronics Industry)", in T. Taniura ed., "Taiwan no Kogyoka - Kokusai Kakokichi no Keisei (in Japanese : Industrialisation of Taiwan)", the Institute of Developing Economies, 1988

[Leu 1989]: Shinkei Leu, "Taiwan no Chushokigyo Mondai to Kokusai Bungyo (in Japanese : Small and Medium-sized Enterprises in Taiwan and International Division of Labour)", Asia Keizai, XXX-12, December $1989,38-56 \mathrm{p}$

[Mizuhashi 2001] : Yusuke Mizuhashi, “Denshi Rikkoku Taiwan no Jitsuzo (in Japanese : Taiwan's Electronics
Based Industrialisation)", JETRO, 2001

[Nihon Keizai Shimbun 1997] : Nihon Keizai Shimbun, “ Polarisation of Semiconductor Industry", Morning edition, 24 December 1997

[Porter 1983] : Michael E. Porter, "Cases in Competitive Strategy", the Free Press, 1983

[Sato 1989] : Yukihito Sato, Taiwan (Chapter 5), Takao Taniura ed., “Ajia no Kogyoka to Chokusetsu Tosi (In Japanese : Industrialisation and Direct Investment in Asian Countries)", the Institute of Developing Economies, 1989

[Sato 1996] : Yukihito Sato, "Taiwan no Keizaihatten ni okeru Seihu to Minkan Kigyo (in Japanese : Government and Private Sector in Economic Development of Taiwan)", in Hattori and Sato ed., "Kankoku Taiwan no Hatten Mekanizumu (in Japanese : Development Mechanism of Korea and Taiwan)", Institute of Developing Economies, 1996

[Shintaku 1994] : Junjiro Shintaku, "Nihon Kigyo no Kyoso Senryaku (in Japanese : Competitive Strategy of Japanese Firms)", Yuhikaku, 1994

[Tanimitsu 2002] : Taro Tanimitsu, "Nichi-Bei-Kan-Tai Handotai Sangyo Hikaku (in Japanese : Comparative Study of Semiconductor Industries of Japan, the US, Korea and Taiwan)", Hakuto Shobo, 2002

[Ying-yi Tu 2001] : Ying-yu Tu, "Appendix C - The Electronics and Information Technology Industries", in Li-min Hsueh, Chen-kuo Hsu and Dwight H. Perkins, “ Industrialization and the State - The Changing Role of the Taiwan Government in the Economy 1945-1998", Harvard Institute for International Development, 2001 [Wade 1990] : Robert Wade, "Governing the Market Economic Theory and the Role of Government in East Asian Industrialisation", Princeton University Press, 1990 